\title{
O MAL-ESTAR NA SALA DE AULA COMO IMPULSO CRIADOR
}

\author{
The Discontent in the Classroom as a Creative Impulse
}

El Malestar en el Aula como un Impulso Creativo

Artigo Original

\author{
Le Malaise dans la Salle de Classe comme une Impulsion \\ Créatrice
}

\section{Resumo}

Este trabalho é parte de um estudo realizado entre os anos de 2010 e 2011 no programa de Mestrado em Educação. O referido trabalho discute o mal-estar presente nas relações que se dão nas salas de aula nos dias atuais, por conta da falta de limites dos adolescentes. Neste artigo, apresentamos a análise de uma aluna de 15 anos de idade, do sexo feminino, que responde parcialmente à demanda da escola enquanto um sujeito plenamente desejante. $\mathrm{O}$ material coletado para a análise se refere a relatos do processo de criação artística e o seu produto final, o objeto de arte desenvolvido pela adolescente. A pesquisa se sustenta nos estudos de Salles sobre os processos de criação artística e em alguns insights psicanalíticos sobre as novas formas de subjetivação de Birman e Forbes e, por fim, na análise do discurso francesa de Michel Pêcheux que entende o discurso como uma malha composta pela história, pela ideologia e pelo inconsciente. Como resultado, constatamos uma mudança de funcionamento psíquico dos alunos da atualidade em relação ao aluno da era moderna. Tal mudança diz respeito a um enfraquecimento da postura desejante em relação à escola e a sua forma de organização como um todo. Em outras palavras, os adolescentes não estão mais vendo a escola como objeto de desejo. Estamos diante de uma ambivalência do sujeito-aluno, um sujeito que, na atualidade, é incapaz de se fazer plenamente desejante como ainda almeja a escola na contemporaneidade.

Palavras-chave: educação; mal-estar; arte; análise do discurso; sujeito desejante.

\section{Abstract}

This work is part of a study undertaken between the years of 2010 and 2011 in a program of Master's in Education. The present work discusses the discontent in relationships that occur inside the classrooms today, due to the lack of limits of teenagers. In this article, we present an analysis of a student at age 15, female, which partially answers the demands of school while a fully desiring subject. The material collected for analysis consisted of reports from the artistic creative process and its final product, the object of art done by teenagers. Our research has as framework the studies of Salles on the processes of artistic creation and some psychoanalytic insights about new forms of subjectivity proposed by Birman and Forbes, and finally, the French Discourse Analysis of Pêcheux who understands the discourse as a knitting composed by history, ideology and the unconscious. As a result, we found a change of psychic functioning of nowadays students in relation to the students of the modern era. This change relates to a weakening of desiring attitude toward school and its organization as a whole. In other words, teens are no longer seeing the school as an object of desire. We are facing an ambivalence of the student subject, a subject who, nowadays, is unable to make himself/herself as fully desiring the way the school still craves in contemporaneity. 
Keywords: education; discontent; art; discourse analysis; desiring subject.

\section{Resumen}

Este trabajo es parte de un estudio realizado entre 2010 y 2011 en el programa de la maestría en Educación. Ese artículo discute el malestar presente en las relaciones que se producen en las aulas hoy en dia, debido a la falta de límites de los adolescentes. En este artículo, presentamos el análisis de un estudiante a los 15 años, sexo femenino, que responde parcialmente a las exigencias de la escuela como un sujeto plenamente deseante. El material recogido para el análisis consistió en informes del proceso de creación artística y de su producto final, el objeto de arte realizado por los adolescentes. Nuestra investigación se basa en estudios de Salles sobre los procesos de creación artística y de algunas ideas psicoanalíticas sobre las nuevas formas de subjetividad Birman y Forbes, y, por último, en el análisis del discurso francesa de Pêcheux que entiende el discurso como una malla compuesta por la historia, la ideología y el inconsciente. Como resultado, vemos un cambio del funcionamiento psíquico de los estudiantes de hoy en relación con el alumno de la era moderna. Este cambio se refiere a un debilitamiento de desear la actitud hacia la escuela y su organización en su conjunto. En otras palabras, los adolescentes ya no están viendo a la escuela como un objeto de deseo. Estamos frente a una ambivalencia del estudiante sujeto, un tipo que, en la actualidad, no está en condiciones de hacer plenamente deseando aún anhelan la escuela en el presente.

Palabras clave: educación; malestar; arte; análisis del discurso; sujeto desean.

\section{Résumé}

Ce travail fait partie d'une étude menée entre 2010 et 2011 dan le programme de maîtrise en 'éducation. Ce document traite $d u$ malaise actuel dans les relations qui se produisent dans les salles de classe aujourd'hui, en raison de l'absence de limites d'adolescents. Dans cet article, nous présentons l'analyse d'un étudiant à l'âge de 15 ans, femelle, qui répond partiellement aux exigences de l'école en tant que sujet désirant pleinement. Le matériel recueilli pour l'analyse consistaient en des rapports du processus de création artistique et son produit final, l'objet d'art fait par des adolescents. Notre recherche est fondée sur des études de Salles sur les processus de la création artistique et à quelques idées psychanalytiques sur les nouvelles formes de subjectivité Birman et Forbes, et enfin, dans l'analyse du discours français de Pêcheux qui comprend le discours comme un maillage composite par l'histoire, l'idéologie et l'inconscient. En conséquence, nous voyons un changement du fonctionnement psychique des étudiants d'aujourd'hui par rapport à l'élève de l'ère moderne. Ce changement concerne un affaiblissement de vouloir attitude envers l'école et leur organisation dans son ensemble. En d'autres termes, les adolescents ne sont plus de voir l'école comme un objet de désir. Nous sommes confrontés à une ambivalence du sujet étudiant, un gars qui, à l'heure actuelle, n'est pas en mesure de faire pleinement désirant encore soif de l'école dans le présent.

Mots-clés: éducation; malaise; art; analyse du discours; sujet désirant.

É dado que na contemporaneidade a Educação vem atravessando momentos difíceis diante da insuficiência de aportes materiais e emocionais para o manejo da violência, do uso indevido de drogas, do fenômeno bullying, de todos os tipos de dificuldades de aprendizagens diagnosticadas ou não e, principalmente, do menosprezo que a maioria dos adolescentes nutre pela escola, pela sua forma de organização e pelos saberes conservados desde a sua constituição.

Nesse contexto, o que mais chama a atenção é justamente o aumento da passividade e da resistência dos adolescentes em relação àquilo que a escola tem a oferecer, ou seja, o estudo orientado, padronizado, organizado por horários e disciplinas em que os conteúdos são transmitidos, discutidos ou problematizados, tendo como pano de fundo uma relação professor-aluno verticalizada e pautada em preceitos morais.

Apesar da promessa da cidadania, boa parte de nossos adolescentes fracassam na tentativa de se tornar o que a escola espera. Como exemplos desse fracasso, podemos mencionar as constantes queixas dos professores em reuniões pedagógicas, de conselho de classe, em reuniões semanais de trabalho pedagógico e em reuniões de pais a respeito das formas como são tratados os conteúdos que ministram e, até mesmo, do desrespeito em nível pessoal. As queixas ainda se relacionam às provas em branco, aos trabalhos que deixam de ser entregues, ao conteúdo da aula não anotado. Porém, nota-se que os mesmos adolescentes que apresentam as atitudes mencionadas são assíduos frequentadores da escola.

Pressupomos, portanto, que nos encontramos num contexto de angústia e mal-estar gerados pela incompreensão, por parte dos docentes, das causas que determinam o menosprezo e a passividade dos adolescentes. Hipotetizamos que nos encontramos paralisados diante de sujeitos-alunos atravessados pelas mudanças sociais do mundo globalizado, um atravessamento que mudou os modos de operar de um sujeito que não pode mais acreditar que a escola seja capaz de inseri-lo numa sociedade singular e complexa.

Diante das considerações, perguntamos: nossos adolescentes ainda são capazes de se fazer objeto de desejo do outro-escola e responder a sua demanda? Nosso objetivo é levantar pontos de questionamentos sobre os adolescentes 
e sua relação com os saberes escolares tendo como corpus os seus próprios trabalhos artísticos e o discurso produzido por eles a respeito de suas produções artísticas.

Para iniciar, no primeiro tópico, apresentaremos os fundamentos teóricos. No segundo tópico, traremos o percurso metodológico e alguns pressupostos da Análise do Discurso de linha Francesa (doravante ADF). No mesmo tópico, apresentamos alguns recortes discursivos do diário de criação de uma adolescente de 15 anos, cursando o $9^{\circ}$ ano em uma escola pública municipal e a nossa análise.

\section{Escola, arte e função paterna}

Neste tópico, propomos algumas reflexões em torno da noção de função paterna e suas relações com a escola e a Arte.

Iniciamos argumentando que a função paterna é uma das noções mais importantes das teorias de Lacan. Para compreender melhor tal formulação, estabelecemos uma relação desta com o mito freudiano do pai primitivo. Com o mito, Freud (1925/2011) postula a legitimação das relações de poder e da lei por todos os membros de uma sociedade que se funda a partir de um pai, "um único macho forte, violento e ciumento" (Freud, 1925/2011, p. 158).

O pai da horda, um déspota sem limites, tomou para si todas as mulheres e matou ou afastou os filhos, seus rivais perigosos. Um dia, porém, esses filhos se juntaram, impuseram-se a ele e o mataram e devoraram, a esse pai que era seu inimigo, mas também seu ideal. (Freud, 1925/2011, p. 158)

Porém, a morte do pai deixou um vazio para os filhos que não puderam assumir a herança, pois cada um estorvava os demais. Sob a influência do malogro e do remorso, aprenderam a se tolerar mutuamente, uniram-se num clã fraterno mediante as regras do totemismo (a proibição do incesto e a proibição de matar o pai). (Freud, 1925/2011, p. 158) Dessa forma, evitou-se a repetição do ato monstruoso.

Então, para Freud, o pai-totem é aquele que submete o sujeito às leis psíquicas e sociais e, dessa forma, passa a ser a metáfora do significante materno inviabilizando o incesto.

Contudo, Lacan (2005) postula que o homem é impedido do gozo incestuoso não pela lei, mas pela linguagem cujo ponto de origem histórica é desconhecido. Lacan (1953/2005) adverte que a linguagem não possui uma significação, mas desempenha um importante papel, ou seja, possui a função de se fazer reconhecer simbolicamente os homens de um grupo e, dessa forma, constitui-lo em Nomedo-Pai, um ato de linguagem que faz emergir a lei e o seu cumprimento.

Portanto, "algo dito mesmo que por uma pessoa que não seja do sexo masculino pode ter o efeito de nomesdo-pai" (Cunha, 2012, p. 110). Então, uma palavra dita pela mãe, pelo professor, pela diretora da escola, pode representar uma intervenção naquilo que por um instante pertenceu à cultura.

Assim sendo, os limites e as leis são cumpridos mesmo longe da presença da autoridade em seu estado material, porque esses limites são "culturalmente construídos e impostos socialmente pela linguagem" (Cunha, 2012, p. 110). Dessa forma, o modelo do Nome-do-Pai é referência para a construção de um laço social baseado na submissão.

A orientação paterna gera as características específicas do laço social moderno. Como exemplos, temos a verticalidade das relações (grupos e hierarquias), a busca da verdade, as perspectivas e os planejamentos do futuro, o diálogo, a razão, a especialização (Forbes, 2012).

Em termos de Educação, o modelo do pai simbólico pode ser representado por uma "escola autoritária, na qual os alunos se levantavam quando o professor entrava em classe e só se sentavam após sua permissão" (Forbes, 2012, p. 123). Para responder à demanda da escola autoritária, o aluno precisa assumir uma posição desejante, ou seja, saber a hora de falar, entrar e sair da sala em tempo marcado e os cadernos devem apresentar a mais perfeita caligrafia sobre o risco de serem rasgados ou censurados. A liberdade de expressão é inexistente e tudo é imposto aos alunos sem a mínima pretensão de escutar-lhes (Forbes, 2012). Assumir uma posição desejante por parte do aluno no contexto da escola autoritária é compreendido por nós como resultado de um desejo fortalecido pelo contexto cultural.

O conceito de desejo, na acepção clássica freudiana, se encontra na teoria do inconsciente e está vinculado à possibilidade de uma realização ou satisfação. Já em Lacan (2002), o desejo é interpretado a partir de uma tradição filosófica, como apetite ou cobiça e está sempre vinculado a uma falta, ou seja, desejar é sempre desejar outra coisa (Roudinesco; Plon, 1998). E é nesse sentido lacaniano que entendemos o sujeito desejante e a posição desejante na escola.

Contudo, em seguida ao modelo de escola autoritária, veio à escola moderna, em que a demanda por uma posição desejante é semelhante. Sendo assim, a escola moderna privilegia a aproximação entre professor e aluno por meio de um distanciamento hierárquico. A base é a preocupação do professor com aquilo "que cada aluno pensa, se posiciona, consagrando o anedótico jargão 'vamos ver e pensar juntos"” (Forbes, 2012, p. 125).

Segundo o autor, os dois modelos mencionados têm "soluções completas: o primeiro ao excluir o que não serve; o outro, ao equilibrar a ambivalência. Nenhum dá lugar à incompletude do saber, testemunha da presença do real, que é o espaço da criação singular" (Forbes, 2012, p. 126).

Por isso, na atualidade, os padrões de relacionamento pautados nas hierarquias e no equilíbrio das ambivalências da época moderna não estão dando conta de acessar as subjetividades adolescentes que desafiam o cotidiano escolar. A psicanálise explica que tais padrões “já não 
funciona(m) como bússola em uma sociedade na qual se radicaliza o discurso coletivo que promove a concepção de homem sem qualidades, livre e igual" (Forbes, 2012, p. 24).

Portanto, o que temos na sociedade globalizada e, em nossas escolas, é um sujeito pulsional e perdido, que desconhece cada vez mais aquilo que o determina. Isso significa que esse sujeito desorientado só pode ser analisado/educado do ponto de vista da pulsão e não da cadeia significante.

O termo pulsional vem de pulsão e é emprestado da teoria freudiana. Em linhas gerais, a pulsão é o representante psíquico de uma fonte somática. Possui as características da peremptoriedade, a origem no corpo, um objetivo e um objeto (Freud, 1905/1996, 1920/2010a). Para Lacan (2008a), a pulsão é sempre parcial, ou seja, não existe lógica na forma como a sexualidade participa da vida psíquica. $\mathrm{O}$ autor "introduz novos objetos pulsionais na teoria freudiana, além das fezes e do seio, a voz e o olhar. E deu-lhes um nome: objetos do desejo" (Roudinesco; Plon, 1998, p. 632).

Dessa forma, no contexto da globalização, há a redução do sujeito orientado pelo Pai da Modernidade ao sujeito consumidor da contemporaneidade (Forbes, 2012).

Assim, na atualidade, o desejo do sujeito e sua capacidade de se fazer objeto do outro é quase apagada e reaparece enfraquecido na evanescência da mercadoria. Para esse novo sujeito, "surgiriam novos sintomas, diferentes dos sintomas freudianos clássicos" (Forbes, 2012, p. 27). Esses sintomas, oriundos da égide da pulsão, entram na escola produzindo sintomas específicos que aumentam os problemas de relacionamento e, consequentemente, a defasagem no aprendizado dos conteúdos e o mal-estar.

Especificamente na disciplina de arte, podemos compreender a grande dificuldade que há por parte desses adolescentes em se deixar atravessar por um discurso desejante, que contorna o vazio (Lacan, 2008b) e propõe certo modo de organização que se aproxima e ao mesmo tempo se distancia do real da pulsão, promovendo uma satisfação mesmo que momentânea. Como exemplo, recorremos a Freud (1930/2010b) quando aborda a satisfação de desejos pela fantasia. Assim se expressa o autor:

Entre essas satisfações pela fantasia se destaca a fruição de obras de arte, que por intermédio do artista se torna acessível também aos que não são eles mesmos criadores. Quem é receptivo à influência da arte nunca a estima demasiadamente como fonte de prazer e consolo para a vida. Mas a suave narcose em que nos induz a arte não consegue produzir mais que um passageiro alheamento às durezas da vida, não sendo forte o bastante para fazer esquecer a miséria real. (Freud, 1930/2010b, p. 37)

Afirmar que a atividade artística não é forte o bastante e gira em torno de um vazio equivale a afirmar que esta é momentânea e nunca atinge o alvo de sua satisfação e, por isso, retorna constantemente para falar por meio das produções, porque "toda forma sensível (...), é falante"
(Rancière, 2009, p. 35).

Se a obra de arte é materialidade falante, então o artista é aquele "que viaja nos labirintos ou nos subsolos do mundo social. Ele recolhe os vestígios e transcreve os hieróglifos pintados na configuração mesma das coisas obscuras ou triviais" (Rancière, 2009, p. 36). Assim, todo artista posiciona-se e elabora o seu vazio constitutivo por meio de um dizer que não se esgota na obra entregue ao público porque toda a obra de arte é um gesto inacabado. A noção de gesto inacabado é empregada por Salles (2009) e

põe em questão o conceito de obra acabada, isto é, a obra como uma forma final e definitiva. Estamos sempre diante de uma realidade em mobilidade. Isto nos permite falar, sob o ponto de vista do artista, em uma estética em criação. (Salles, 2009, p. 29)

Dessa forma, a autora problematiza a noção de conclusão da obra, caindo "por terra a ideia da obra entregue ao público como sacralização da perfeição" (Salles, 2009, p. 29). Sob esse ponto de vista, o artista apreende a realidade com características que ele mesmo a oferece "dentro de um contexto histórico, social e artístico. Um movimento feito de sensações, ações e pensamentos, sofrendo intervenções do consciente e do inconsciente" (Salles, 2009, p. 29).

Ao transpor as reflexões realizadas até o momento para o contexto de sala de aula, acreditamos ser possível acessar as subjetividades adolescentes por meio do discurso sobre os próprios trabalhos de arte que realizam e rastrear as marcas dos novos posicionamentos psíquicos da contemporaneidade em relação aos saberes escolar e ao mal-estar em sala de aula e, dessa forma, apontar as marcas de um deslocamento do mal-estar para um impulso criador.

O impulso é compreendido por nós como medida de trabalho e soma de forças que impelem o sujeito a alcançar o seu objetivo, no caso, responder à demanda escolar por um aluno estudioso, obediente e que vê nos saberes escolar a possibilidade de planejar o futuro em direção ao emprego e à cidadania.

A seguir, apresentamos o percurso metodológico e instrumento de análise que se vale das teorias da Análise do Discurso de linha francesa de Michel Pêcheux mais precisamente em seu diálogo com a psicanálise.

\section{O percurso metodológico e a Análise do Discurso de linha Francesa}

A ADF tem como objeto de estudo o discurso. Segundo Fernandes (2005, p. 20), o discurso "não é a língua, nem texto, nem fala, mas (...) necessita de elementos linguísticos para ter uma existência material". Por isso, o discurso refere-se a aspectos sociais e ideológicos dos dizeres em nosso cotidiano e podem revelar posições socioideológicas 
que os sujeitos assumem.

Portanto, o discurso distancia-se da língua enquanto comunicação e transmissão de informações, por isso, o sentido não é único e passa a ser encarado como efeitos dos significantes e efeitos de sentidos entre os falantes (Orlandi, 2007).

Somados a uma constituição sócio-histórica, os sujeitos são atravessados também pelo inconsciente, ou seja, por "manifestações de natureza psíquica do/no sujeito, que fogem ao âmbito de sua consciência, que não se manifestam de acordo com sua vontade, mas afloram nos sonhos, nos atos falhos, nos lapsos etc." (Fernandes, 2005, p. 40).

Ao considerar a emergência do inconsciente na fala ou, em nosso caso, nos discursos sobre os próprios processos criativos, consideramos o sujeito-aluno enquanto alguém que desconhece o fato de que, sobre as palavras que diz, outras sempre estão ditas. Nesse sentido, "o sujeito tem a ilusão de ser o centro do seu dizer, pensa exercer o controle dos sentidos do que fala, mas desconhece que a exterioridade está no (seu) interior" (Fernandes, 2005, p. 40), ou seja, é exterioridade social.

Então, o entrecruzamento dos pressupostos da ADF e a arte nos levaram a problematizar as experiências de sala de aula ao fazer falar os adolescentes por meio do discurso sobre o objeto criado. Os adolescentes a que me refiro são de uma escola pública municipal de educação básica, situada na periferia de uma cidade do interior paulista.

A escola foi fundada no ano de 2000 e o maior problema que enfrentamos é a resistência e a passividade diante de suas responsabilidades para com a própria vida escolar e a aprendizagem.

Para tornar possível nossa discussão foi preciso a criação de uma ferramenta pedagógica que chamamos de Diário da Criação (doravante DC). A invenção dos DCs tem por base as teorias de Salles (2009) sobre os processos de criação artística de artistas brasileiros e de várias partes do mundo e de diferentes períodos da história. A autora investiga os manuscritos desses artistas e tece reflexões sobre as maneiras como suas obras são construídas e entregues ao público.

Tais manuscritos podem assumir os formatos de:

Diários, cadernos de anotações ou notas esparsas que acolhem essa forma sensível no primeiro suporte disponível, que carregam ideias ou formas em estado germinal. [...] São registros feitos na linguagem mais acessível no momento em que aparecem e que ficam à espera de uma futura tradução (Salles, 2009, p. 61).

Então, com base nos pressupostos de Salles (2009) citados anteriormente, aos adolescentes foi permitido relatar em seus DCs tudo o que viesse em suas cabeças e, dessa forma, possibilitar uma escuta que permitisse apontar e rastrear sobre os não-ditos de discursos singulares, algo que indique marcas de desejo e de deslocamentos psíquicos nesse sujeito da globalização.

É importante salientar que a professora na posição de pesquisadora procurou não transgredir em nada aquilo que se configura como regra geral para toda uma rede de educação, ou seja, o currículo e a rotina de estudos. A única solicitação feita aos alunos foi que relatassem a forma como criam seus trabalhos de arte da forma como desejassem. Os diários de criação (DCs), ou seja, a sistematização num caderno foi uma sugestão.

Com o passar do tempo, foi observado que os cadernos prevaleceram e, no final do ano de 2010, contava-se com mais de 100 DCs. Em meio a todos esses escritos, alguns chamaram a atenção. Destacamos aqui o DC de Etna (nome fictício), uma aluna de 15 anos que estava cursando o $9^{\circ}$ ano pela segunda vez.

Etna é classificada como indisciplinada, desinteressada e portadora de inúmeras dificuldades de aprendizagem, contudo, o seu processo de criação artística, de uma instalação para o pátio do prédio escolar, nos despertou interesse por revelar um movimento de busca por atender à demanda da escola, mesmo odiando sua rotina e suas exigências.

Passemos à análise de alguns recortes discursivos (doravante RD) presentes nos materiais coletados, todos retirados do diário de Etna. Vejamos um primeiro momento de seu relato:

Meu nome é M. tenho 15 anos. Sou uma garota que gosta de ouvir rock pesado como Aerosmith, coisas desse tipo, gosto também de jogar futsal, na verdade eu jogo na seleção de [nome da cidade], gosto de desenhar adoro desenhar ou jogar bola nas horas vagas como feriado ou dia comemorativo, odeio ir à escola, alguns dos meus colegas dizem que sou louca porque eu faço coisas absurdas gosto de zuar com os outros, é gostoso ir em emoções diferentes. (RD1)

No processo da escrita, o trecho acima nos revela uma garota que gosta do rock pesado dos anos 70 . Buscando os fundamentos desse gênero musical, Fiore e Contani (2011, p. 11) explicam que os Estados Unidos e o Reino Unido, no início dos anos 70, traduzem em som as contradições de uma época, "na qual incentiva a moda e a contracultura (com seus ideais de liberdade total) ao mesmo tempo em que há o esforço dos governos para controlar as aberturas políticas e culturais".

Então, a fala dos autores nos revela que o rock pesado não se trata de música apenas, mas de todo um estilo de vida que marca os sujeitos da década de 70 e, que na contemporaneidade, é adotado por Etna, assim como por "grande parte (de um público) advindo do baixo extrato social" (Fiore; Contani, 2011, p. 11). A identificação de Etna, portanto, não se restringe à música, mas tem todo um 
sentido político e revela uma posição sujeito que concebe o outro como possibilidade de viver "emoções diferentes", fazer "coisas absurdas" e "zuar com os outros" na busca de uma satisfação.

Nessa etapa de seu relato, Etna coloca o ódio à escola como forma de manifestar o seu desprezo por tudo àquilo que a instituição prega contrariando as ideologias dos adeptos do rock pesado. Na escola, não há busca por prazer, há trabalho para aprender os conteúdos, as normas disciplinares, a convivência em sociedade e a cidadania. Esse trabalho é manifesto também na disciplina de Arte que, historicamente, é uma disciplina que evoca o prazer gratuito, sobretudo, por meio do discurso da livre expressão cunhado na Modernidade.

Porém, após 1998 e a instituição dos Parâmetros Curriculares Nacionais de Arte (1998), documento que norteia e unifica o ensino de arte no país, esse prazer da livre expressão sofreu um encolhimento e a disciplina tem um maior direcionamento, sobretudo se considerarmos o foco na arte contemporânea. Esse fato oferece uma abertura maior para o trabalho em sala de aula assumir características mais democráticas, porque, contraditoriamente, é o que se exige nos discursos da educação na contemporaneidade.

Por isso, optamos por trabalhar com as instalações. Durante nossos estudos, Etna se viu identificada com a aula e a possibilidade de expressar o que sente diante do prazer barrado pelas normas escolares.

Vejamos outro momento de seu relato:

Estava pensando em fazer um quadro mas, é muito troxa agora depois do resumo da Regina Silveira "Gone Wild" tive uma sensação de a minha obra vai ser totalmente diferente. (...) Estou pensando em fazer no banheiro masculino pelo lado de fora, colocar vários tipos de cartolinas coloridas na parede e desenhar colar partes do corpo humano de jogar tinta e misturar para não ter nada a vê. Para que o público pense como é o cúmulo do absurdo um desenho tão idiota. (...) Também mostrar como nossas mentes são onuportunos no fundo ser tosco. (...) Mas com certeza todos vão perguntar para si mesmos o que significa aquilo que estão vendo. (RD2)

No trecho acima, podemos perceber a preocupação de Etna com a atividade artística que lhe foi proposta através do enunciado "Estava pensando em fazer um quadro". O dizer do sujeito leva a refletir que, em algum momento de sua vida escolar, parou para pensar e planejar algo em longo prazo o que revela uma postura diferente do RD1.

Em seguida, porém, deparamo-nos com a adversidade representada pela conjunção "mas" e a conclusão de que sua ideia "seria muito troxa" (sic). Segundo o dicionário Aurélio (Ferreira, 1989, p. 690), a palavra 'trouxa' se refere a uma "pessoa tola, fácil de enganar", porém, o efeito de sentido de tal palavra no contexto de produção do discurso de Etna a respeito de um quadro pode suscitar também algo tolo ou sem originalidade diante de sua posição psíquica diante da vida que remete ao radical do rock e à complexidade das instalações.

Contudo, a conclusão que Etna chega a respeito de sua ideia inicial não é espontânea, mas entendida por nós como resultado de um processo identificatório com a artista plástica Regina Silveira e sua obra Gone Wild estudada em sala de aula. É essa identificação que pode ter levado o sujeito enunciador a revelar que teve uma sensação de que sua obra ia ser "totalmente diferente" assim como se autodenomina e, de manifestar a sua diferença no processo de construção do trabalho escolar e, ao mesmo tempo, responder ao que lhe é demandado.

É nesse sentido que o sujeito enunciador evoca a arte de Regina Silveira, artista multimídia, gravadora, pintora, professora, cuja poética reflete a questão da dilaceração do indivíduo na sociedade contemporânea (...). Várias de suas obras remetem a discussões sociais e políticas, permitindo reflexões sobre o poder como em Monumento (1987) ou The Saint's Paradox (1994); sobre a violência, em Encuentro (1991); ou sobre o papel social da mulher, como em Carrinho de Chá (1986) (Instituto Cultural Itaú, 2011).

Todas as questões, elencadas no trecho acima e problematizadas pela artista em seu trabalho, refletem o pensamento da arte contemporânea que, segundo Bauman (1998), não tem a preocupação de revelar a verdade do mundo, mas refletir a vida, somando-se aos seus conteúdos. Dessa forma, "as imagens não representam, mas simulam" (Bauman, 1998, p. 135), criam e portam significados "num mundo notório por ser simultaneamente afortunado e flagelado pela insuficiência e pelo excesso de significados" (Bauman, 1998, p. 135).

Assim entendemos a obra de Regina Silveira, como algo que não se propõe a denunciar a realidade através de seu estilo, mas que se soma ao mundo e à polifonia dos discursos, ou seja, um conjunto de diferentes vozes que constituem os sujeitos. Especialmente em Gone Wild, essa polifonia se evidencia quando a artista relata o processo de criação da obra.

Podemos argumentar que o contato de nosso sujeito de pesquisa com a inserção da artista na cultura americana para a realização de Gone Wild foi o que levou Etna a considerar sua primeira hipótese de trabalho como algo "muito troxa" (sic).

Então, Etna opta por "fazer no banheiro masculino pelo lado de fora, colocar vários tipos de cartolinas coloridas na parede e desenhar colar partes do corpo humano de jogar tinta e misturar para não ter nada a vê" (sic). Pelo enunciado podemos entender que por meio de um processo identificatório, o sujeito enunciador responde à demanda da professora e da escola, apropriando-se das informações com liberdade de pensamento e abertura para criar e elaborar a sua angústia, a mudar o seu projeto e executá-lo, mesmo 
que este não tenha "nada a vê" (sic), com o "banheiro masculino" como espaço de execução.

Nesse sentido, o sujeito enunciador revela que o que importa é o seu desejo de executar o trabalho, mostrando "como nossas mentes são onuportunos no fundo ser tosco" (sic). Tal enunciado chama a atenção pela presença das palavras “onuportunos” que lembra ‘inoportuno' e a palavra 'tosco'.

Se recorrermos ao dicionário Aurélio (Ferreira, 1989, p. 390), veremos que o significado da palavra 'inoportuno' é 'intempestivo', imprevisto, imprevisível e 'tosco' é algo que existe "tal como veio da natureza, não lapidado nem polido; grosseiro; rude; sem instrução” (Ferreira, 1989, p. 678).

Tais palavras, porém, são empregadas como críticas às "nossas mentes" e não à minha mente, o que nos leva a pensar que Etna atribui a outras pessoas, além dela própria, as qualidades de imprevisíveis, rudes e grosseiras. Interpretamos que tais pessoas são aquelas que comporão o seu "público" e somente poderão ser encontradas no contexto de produção de seu trabalho, ou seja, no contexto escolar, referindo-se tanto aos alunos quanto aos professores e equipe gestora.

Então, é esse "público" que nosso sujeito de pesquisa deseja que "pense como é o cúmulo do absurdo um desenho (projeto) tão idiota". O público não entenderia seu trabalho, e ela se pergunta como "o cúmulo do absurdo um desenho (projeto) tão idiota” por ser rude e grosseiro ou por não entender que a mente de sua autora é imprevisível? Eis a provocação de Etna que, "com certeza", fará com que todos perguntem e reflitam sobre "o que significa aquilo que estão vendo", ou seja, o sujeito da pulsão atuando no cenário do desejo. Em outras palavras, um sujeito pulsional que encontrou meios para sobreviver num contexto desejante.

Entendemos, portanto, que o trecho destacado do discurso de Etna revela um percurso criador que se caracterizou por uma busca que envolveu investimento de tempo e afeto. Interpretamos tal busca como um desejo de se mostrar ao outro-escola, de se fazer compreender e ao mesmo tempo de tentar responder a demanda desse outro.

Em seguida, apresentamos a instalação de Etna.

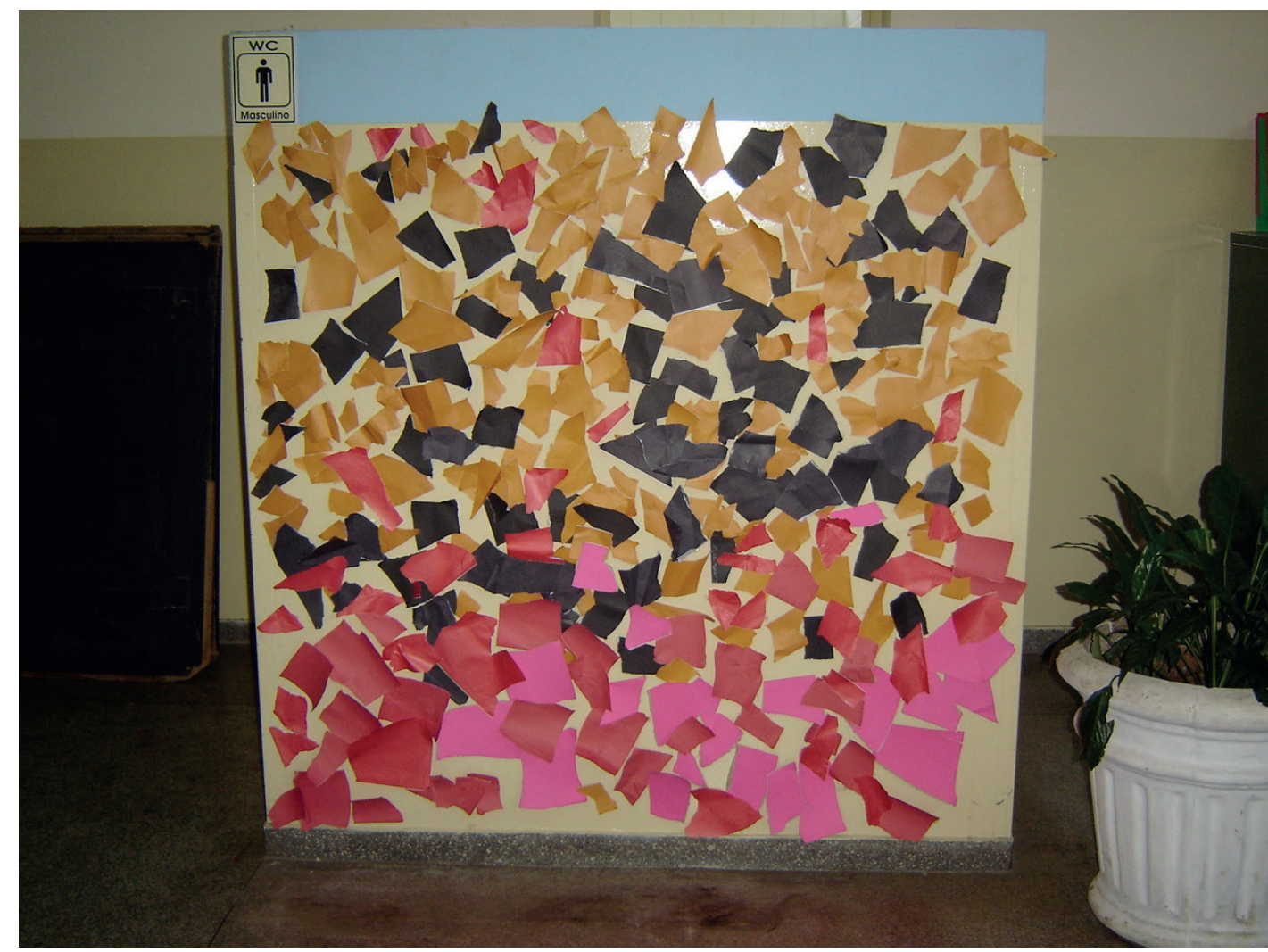

Figura 1. Etna. Sem título. 2010. Instalação. 2.0m x 1.5m. Cartolina colorida e fita adesiva sobre biombo de concreto. 
Enquanto arte do espaço, a instalação é uma linguagem artística que possui como característica principal o caráter híbrido, ou seja, uma fusão das linguagens artísticas (música, dança, artes cênicas e visuais) tanto na técnica quanto no tema. Tal característica contribui ainda mais para enriquecer a forma (objeto artístico) e o conteúdo (o que nos leva a refletir sobre a obra, o invisível na forma) e suscitar reflexões. Sendo uma modalidade da arte contemporânea, as instalações permitem infinitas explorações de ideias ao propor que o público entre no espaço expositivo sem noção nenhuma daquilo que verá e ao sair tenha refletido sobre algo.

Então, em virtude da complexidade da produção de uma instalação, esta não faz parte dos interesses da maioria dos adolescentes presentes em nossa realidade escolar e esse fato é o que chama a atenção em primeiro lugar em relação à produção artística apresentada por Etna ao final de seu percurso, ou seja, a decisão de abandonar um projeto pictórico tradicional, ou seja, uma composição figurativa em tela e pintada a óleo.

Contudo, argumentamos que a escolha do espaço, ou seja, o biombo do banheiro masculino se deu em virtude de ser um espaço de destaque na escola e de grande circulação de pessoas. Por isso, acreditamos que a principal intenção de Etna é se fazer notar pela ousadia presente em sua identificação com Regina Silveira e com o rock pesado.

Em primeiro lugar, o espaço é pensado como uma enorme tela em que uma pintura poderia ser feita, porém, diante da impossibilidade de pintar com tinta a parede da escola e ser advertida, a adolescente-artista busca outras soluções em materiais de fácil acesso e que não comprometa a preservação do patrimônio. Assim sendo, o papel é rasgado com as mãos e aplicado aleatoriamente na parede como numa erupção de sentimentos que afloram automaticamente.

A atitude de colar papel rasgado com as mãos, sem o zelo, o capricho e o planejamento tradicionalmente exigidos num trabalho escolar, faz lembrar as pinturas de Jackson Pollock, um americano precursor da pintura de ação e que não se encaixava nos padrões da arte em vigor na Europa e na América no final da década de 1940.

Segundo Gombrich (1995), a pintura de ação ou expressionismo abstrato é uma modalidade de pintura em que o artista precisa ceder aos impulsos espontâneos por meio de uma execução rápida. Por isso, explica-nos o autor, as ações "não devem ser premeditadas; pelo contrário, devem assemelhar-se a um impulso espontâneo". Nesse sentido, a atitude de Etna e a colagem aleatória remetem à pintura de ação devido ao fato de não haver a preocupação de planejar a disposição das cores dos pedaços de papel. Naquele momento, a adolescente-artista apenas preocupase em preencher um espaço vazio real.

Após o ato da colagem o que temos é uma composição pesada pela organização das cores. Quando focamos nosso olhar no todo, inevitavelmente nos fixamos no fundo preto que transmite uma sensação de que as outras cores emergem de um vácuo.

A abstração da produção remete à subjetividade da adolescente-artista que deixa aflorar sentimentos desconhecidos dela mesma e confusos na tentativa de atender a uma solicitação de trabalho escolar.

\section{Considerações finais}

As discussões desenvolvidas no presente artigo pretenderam mostrar uma das formas como a adolescente do universo estudado, concebida por nós como sujeito desorientado, pode se subjetivar em contexto escolar, por meio da expressão da sua angústia em atividades artísticas.

Historicamente, desde a escola autoritária até à escola moderna, o papel da instituição tem sido de orientar os sujeitos nas atitudes e nos valores que irão servir de base na construção da sua cidadania.

Porém, o que encontramos em nossas salas de aula na atualidade está longe de ser o estudante da Modernidade, isto é, o sujeito Pai-orientado. Hoje, deparamo-nos com novas formas de subjetivação (Birman, 2007), próprias da cultura da globalização, isto é, sujeitos desorientados e atravessados pela pulsão.

Assim sendo, encontramo-nos diante de uma mudança psíquica crucial e irreversível, cujas manifestações não podem ser decifradas pelas vias do simbólico e tampouco manejadas tendo por base uma relação verticalizada, hierarquizada, padronizada e moralizada como na Modernidade. Portanto, argumentamos que nosso sujeitoaluno é um sujeito dividido entre a cultura globalizada que o constitui e a demanda da instituição por um sujeito orientado e desejante.

$\mathrm{Na}$ tentativa de acessar essas subjetividades ambivalentes, valemo-nos do discurso da arte que fala por meio das formas sensíveis. Velendo-nos da arte e de diários de processo como ferramenta pedagógica, emprestamos escuta, voz e oportunidade para que os alunos pudessem explorar e problematizar a si mesmo e o outro-escola.

O percurso criativo de Etna revela movimentos do pensamento que englobam sua relação com o mundo e ela mesma. Encontramos em seu discurso, marcas psíquicas que apontam um deslocamento subjetivo de um sujeito adepto da cultura do rock e do prazer a qualquer custo para um sujeito que se identifica com um dado conteúdo escolar caracterizado pela complexidade da linguagem e elaboração pessoal, no caso, a artista Regina Silveira e sua obra Gone Wild.

O objetivo da apresentação da linguagem da instalação e do percurso criativo de Regina Silveira foi o de oferecer uma ferramenta para a elaboração pessoal e singular, articulando a liberdade de criação (resposta à demanda) com 
a responsabilidade de realização como opção do sujeito.

Acrescentamos, também, que Etna não construiu apenas um trabalho escolar, mas a si mesma numa perspectiva ética e estética.

Finalmente, salientamos que o propósito de nossa discussão não foi o de propor técnicas ou metodologias em Arte, mas mostrar que enquanto espaço de expressão da angústia, esta poderá auxiliar a escola na difícil tarefa de acessar as novas subjetividades construídas pela cultura contemporânea.

Nosso objetivo também não foi o de tecer críticas à instituição escolar e suas práticas, mas propor uma reflexão em torno de um sujeito que mudou psiquicamente. Assim sendo, o desafio volta-se para a reinvenção das formas de convivência entre professor e aluno, uma convivência que considera o saber como incompleto, atravessado pelo real e que possibilita a abertura para a criação singular (Forbes, 2012) e, porque não uma abertura para a recusa? Então, "como pensar um modelo prático dessa Escola Lacan, que inscreve o silêncio, o real no amor do saber?" (Forbes, 2012, p. 127).

\section{Referências}

Bauman, Z. A. (1998). O mal-estar da pós-modernidade. Rio de Janeiro: Jorge Zahar.

Birman, J. (2007). Mal-estar na atualidade: A psicanálise e as novas formas de subjetivação (6a ed.). Rio de Janeiro: Civilização Brasileira.

Brasil (1998). Parâmetros Curriculares Nacionais: arte/ Secretaria de Educação Fundamental. Brasília, MEC/ SEF.

Cunha, A. S. (2012). Famílias não tradicionais e problemas na escola. In M. R. Pereira (Org.), A psicanálise escuta a educação: 10 anos depois (pp. 109-122). Belo Horizonte: Fino Traço/FAPEMIG.

Fernandes, C. (2005). Análise do Discurso: Reflexões introdutórias. Goiânia: Bandeirante.

Ferreira, A. B. H. (1989). Novo dicionário da língua portuguesa ( $7^{\mathrm{a}}$ ed.). Curitiba: Positivo.

Fiore, A. A., \& Contani, M. L. (2011). Das formas báquicas e do grotesco Bakhitiniano em imagens do heavy metal e do hard rock. Revista Domínios da Imagem n8 (pp. 7-18). In Anais do III Encontro Nacional de Estudos da Imagem, 3 a 6 de maio de 2011, UEL Universidade Estadual de Londrina.
Forbes, J. (2012). Inconsciente e responsabilidade: Psicanálise do século XXI. São Paulo, Manole.

Freud, S. (1996). Três ensaios sobre a teoria da sexualidade. In J. Strachey (Ed.) Edição standard brasileira das obras completas de Sigmund Freud (Vol. 7, pp. 119. 231). Rio de Janeiro: Imago. (Originalmente publicado em 1905)

Freud, S. (2010a). Além do Princípio do Prazer. In S. Freud, Sigmund Freud Obras Completas (Vol. 14, pp. 161239). São Paulo: Companhia das Letras. (Originalmente publicado em 1920)

Freud, S. (2010b). O Mal-Estar na Civilização. In S. Freud, Sigmund Freud Obras Completas (Vol. 18, pp. 13-122). São Paulo: Companhia das Letras. (Originalmente publicado em 1930)

Freud, S. (2011). Autobiografia. In S. Freud, Sigmund Freud Obras Completas (1923-1925) (Vol. 16, pp. 75-167). São Paulo: Companhia das Letras. (Originalmente publicado em 1925)

Fundação Bienal de São Paulo. (2010). Em Nome dos Artistas (Educativo - livreto sobre a 29a Bienal). Coleção Astrup Fearnley Museum of Modern Art.

Gombrich, E. (1995). A História da Arte. Rio de Janeiro: LTC.

Instituto Cultural Itaú (2011). Enciclopédia digital. Recuperado de http://enciclopedia.itaucultural.org.br/ pessoa8084/regina-silveira, Acesso em 19/09/2011.

Lacan, J. (2002). Seminário, livro 6: O desejo e sua interpretação (1958-1959). Porto Alegre: Associação Psicanalítica de Porto Alegre.

Lacan, J. (2005). Nomes-do-Pai. Rio de Janeiro: Jorge Zahar.

Lacan, J. (2008a). Seminário, livro 11: Os quatro conceitos fundamentais da psicanálise. Rio de Janeiro: Jorge Zahar.

Lacan, J. (2008b). Seminário, livro 7: A ética da psicanálise (1959-1960). Rio de Janeiro: Jorge Zahar.

Orlandi, E. P. (2007). Análise de Discurso: Princípios e procedimentos (7a ed.). Campinas, SP: Pontes.

Rancière, J. (2009). O Inconsciente estético. São Paulo: Ed. 34. 
Roudinesco, E., \& Plon, M. (1998). Dicionário de Psicanálise. Rio de Janeiro: Zahar.

Salles, C. A. (2009). Gesto Inacabado: Processo de criação artística. São Paulo: FAPESP: Anablume.

\section{Endereço para correspondência:}

Robineia da Costa Seraphim

Endereço: Rua Treze de Maio, no 585. Morungaba/SP.

CEP: $13260-000$

E-mail: robineia.costa@gmail.com

Endereço para correspondência:

Márcia Aparecida Amador Mascia

Endereço: Rua João Simões da Fonseca, 362. Campinas/

SP. CEP: 13085-050

E-mail: marciaaam@uol.com.br 